\title{
Cross-National Comparison between U.K. and U.S. Higher Education Students in Test Anxiety
}

\author{
Patricia A. Lowe ${ }^{1}$ \\ ${ }^{1}$ Department of Educational Psychology, University of Kansas, Lawrence, Kansas, USA \\ Correspondence: Patricia A. Lowe, Department of Educational Psychology, University of Kansas, Lawrence, KS, \\ 66045, USA. Tel: 1-785-864-9710. E-mail: tlowe@ku.edu
}

Received: June 14, 2019

Accepted: June 28, 2019 Online Published: July 18, 2019

doi:10.5539/hes.v9n3p88

URL: https://doi.org/10.5539/hes.v9n3p88

\begin{abstract}
A cross-national comparison was conducted between U.K. and U.S. higher education students on the Test Anxiety Measure for College Students (TAM-C). The TAM-C was administer to 1,776 U.K. and U.S. higher education students online. The results of tests of measurement invariance found the TAM-C invariant across country and gender. In addition, results of a MANOVA and follow-up ANOVAs indicated U.K. higher education students were more test anxious than U.S. higher education students and females were more test anxious than males. Implications of the findings for mental health professionals who work with higher education students in the United Kingdom and the United States are discussed.
\end{abstract}

Keywords: cross-national differences, gender differences, higher education students, test anxiety, United Kingdom, United States

\section{Introduction}

A dearth of research has been conducted on cross-national comparisons in the area of test anxiety between U.K. and U.S. students. Only one published study has been conducted to date to the author's knowledge over 60 years ago in the area of test anxiety between U.K. and U.S. elementary/primary students. Culture is believed to impact the symptom presentation and intensity of test anxiety students' experience (Bodas \& Ollendick, 2005; Lowe et al., 2008; Zeidner, 1998). In the present study, country and gender differences were explored in a sample of U.K. and U.S. higher education students on a new measure of test anxiety to address the gap in cross-national comparisons in the area of test anxiety among students from these two countries. Some of the features of the new measure, the Test Anxiety Measure for College Students (TAM-C), when combined make this instrument different from other measures. More specifically, the TAM-C is a multidimensional instrument, it includes a facilitating anxiety scale, and it was scaled only on higher education students (Lowe, 2018a, 2019b).

A growing number of higher education students are reported to experience increasingly high levels of distress worldwide (Sharp \& Theiler, 2018; Yusufov, Nicoloro-SantaBarbara, Grey, Moyer, \& Lobel, 2019), including postsecondary students in the United Kingdom and the United States (American College Health Association, 2014; Royal College of Psychiatrists, 2003; Scanlon, Rowling, \& Weber, 2007; Singleton, Bumpstead, O-Brien, Lee, \& Meltzer, 2001; University of Leicester, 2002). Test anxiety, anxiety experienced in testing situations, has been identified as one of those areas of major distress for higher education students (Furr, Westegeld, McConnell, \& Jenkins, 2001; Szafranski, Barrera, \& Norton, 2012) and it is a concern, as it is reported to be related to poorer classroom test performance, lower grades, lower self-esteem, higher levels of neuroticism (von der Embse, Jester, Roy, \& Post, 2018), and school dropout (Gerwing, Rash, Gerwing, Bramble, \& Landine, 2015). Thomas, Cassady, and Finch (2018) found in their study that about a quarter of their undergraduate sample experienced high levels of test anxiety. With this many students possibly experiencing high levels of test anxiety, it would be important for mental health professionals who work with students in higher education institutions to identify test-anxious students early, so they can receive the appropriate assistance needed to reduce their test anxiety.

\subsection{United Kingdom, United States, Gender, and Test Anxiety}

One cross-national comparison study has been published to date to the author's knowledge in the area of test anxiety between U.K. and U.S. students. This cross-national comparison involved a sample of primary/elementary students, not higher education students, with U.K. primary students reporting higher levels 
of test anxiety than U.S. elementary students (Sarnoff, Lighthall, Waite, Davidson, \& Sarason, 1958). Therefore, a study that examined differences in the intensity and symptom presentation of test anxiety in higher education students in the United Kingdom and the United States would be helpful in addressing this gap in the literature.

Education is considered a cultural factor (Zeidner, 1998) and differences have been found in the educational systems in the United Kingdom and the United States (Institute of Educational Sciences, 2016; Luthra \& Flashman, 2017; Triventi, 2014) and may account for differences in test anxiety students' experience in these two countries. The U.S. university system is reported to provide greater access to those individuals seeking a bachelor's degree than the U.K. university system. In addition, it takes three years to complete a bachelor's degree in the United Kingdom compared to four years in the United States. Moreover, when students apply to a university in the United Kingdom, they also apply for a major at the time they submit their application, whereas students do not typically apply for a major when they apply for admissions to a university in the United States. Also, the cost to attend a higher education institution in the United States is higher than in the United Kingdom (Luthra \& Flashman, 2017). Furthermore, accountability to external factors is reported to be higher among U.S. universities than U.K. universities (Triventi, 2014). As a result, U.S. students, faculty, and administrators are more likely to experience pressure to produce positive educational outcomes, including positive student test results than U.K. students, faculty, and administrators and this difference in accountability may help explain any difference, if any difference exists, in the intensity and symptom expression of test anxiety experienced between students from the United Kingdom and the United States.

Past research has found that females report more test anxiety than males on instruments used to assess the test anxiety construct in many different countries around the world (Zeidner \& Matthews, 2005). Moreover, these

differences appear as early as elementary school (Lowe, Grumbein, \& Raad, 2011; Zeidner, 1998) and continue to be reported through the undergraduate and graduate school years (Chapell et al., 2005; Hembree, 1988; Hojat et al., 1999; Lowe, 2018a, 2019a). Different explanations have been proffered for the differences in anxiety, including the way individuals are socialized (Schaefer, Watkins, \& Burnham, 2003; Sutton \& Farrall, 2005) and neurobiological differences (Lewinsohn, Gotlib, Lewinsohn, Seeley, \& Allen, 1998). In contrast, the relationship between facilitating anxiety and gender is less clear, with some studies reporting no differences in facilitating anxiety (Lowe, 2018a, 2019b) and other studies finding less facilitating anxiety in females than in males (Hembree, 1988).

\subsection{Test Anxiety Measure for College Students}

The TAM-C is a multidimensional instrument of test anxiety for use with higher education students. The TAM-C was developed in the United States (Lowe, 2018a) and it is based on the biopsychosocial model of test anxiety where intrapersonal characteristics interact with contexts, and threat appraisal of the test to produce the intensity and symptom presentation (i.e., physiological, behavioral, and cognitive symptoms) of test anxiety as well as facilitating anxiety (Lowe et al., 2008). Lowe (2018a) scaled the measure with the responses of 360 U.S. postsecondary students and found a model consisting of one facilitating anxiety factor and five test anxiety factors to be the best model for the TAM-C. Along with the Facilitating Anxiety factor, the TAM-C has a Physiological Hyperarousal factor, Task Irrelevant Behaviors factor, Cognitive Interference factor, Worry factor, and Social Concerns factor. The six-factor model has also been reported in studies with Canadian and Australian undergraduate students (Lowe, 2018b, 2019b).

The purpose of the study was to examine country and gender differences between U.K. and U.S. higher education students on a new measure of test anxiety, the TAM-C. Prior to examining country and gender differences, tests of measurement invariance were conducted to determine whether the construct was equivalent across groups. Psychometric equivalence on the construct of interest is required prior to examining group differences (Putnick \& Bornstein, 2016). The author hypothesized the following:

Hypothesis 1: The construct of test anxiety would be found to be psychometrically equivalent across country (United Kingdom, United States) and gender (male, female) on the TAM-C.

Hypothesis 2: U.S. students would score higher than U.K. students on the TAM-C test anxiety scales.

Hypothesis 3: Females would score higher than males on the TAM-C test anxiety scales.

Hypothesis 4: Male-female differences would not be reported on the TAM-C facilitating anxiety scale.

\section{Method}

\subsection{Participants}

The higher education students for the present study consisted of 1,776 undergraduates from the United Kingdom 
$(n=531)$ and the United States $(n=1,245)$. The students ranged in age from 18 to $26(M=21.15, S D=2.40)$. There were $808(45.5 \%)$ males and $968(54.5 \%)$ females. The ethnic distribution of the U.K. sample was Asian (8.9\%), Black (2.6\%), Mixed/Multiracial (5.1\%), White (81.5\%), and other (1.9\%) and the ethnic composition of the U.S. sample was Asian (9.3\%), African American/Black (13.8\%), Caucasian/White (51.1\%), Hispanic (17.1\%), Multiracial (4.9\%), Native American/Alaskan Native (1.0\%), and other (2.9\%). The U.K. and U.S. students were recruited through Qualtrics, a U.S. web-based survey company. The students were part of a Qualtrics panel.

\subsection{Instrument}

The 43 item TAM-C includes six scales, five of these scales assess test anxiety and one scale measures facilitating anxiety. The five test anxiety scales include Worry, Social Concerns, Cognitive Interference, Task Irrelevant Behaviors, and Physiological Hyperarousal. The Worry scale measures anxious thoughts about failing tests and consequences associated with failure. The Social Concerns and Cognitive Interference scales assess concerns the student has about the reactions of faculty, peers, and parents (i.e., significant others) to one's possible failure on tests and distracting and pejorative thoughts that keep a student from concentrating on tests, respectively. The Task Irrelevant Behaviors scale and the Physiological Hyperarousal scale measure avoidance behaviors in relation to evaluative situations and autonomic reactions associated with evaluative situations, respectively. The Facilitating Anxiety scale assesses the slight anxiousness experienced in testing situations resulting in improved test performance. All scales consists of 7 items, with the exception of the Task Irrelevant Behaviors scale and Worry scale, which includes 6 and 8 items, respectively. The TAM-C has a 4-point scale, with anchors ranging from 1 (never) to 4 (almost always; Lowe, 2018a). Internal consistency reliability estimates of .75 to .92 were reported for the TAM-C scores in a U.S. higher education sample of 360 students. Factorial, convergent, and discriminant validity evidence providing support for the TAM-C scores has been found (Lowe, 2018a).

\subsection{Procedures}

The present study was part of a larger study examining test anxiety in different countries on the TAM-C. U.K. and U.S. students completed demographic information requested and measures online using the Qualtrics electronic platform. Consent was obtained from the U.K. and U.S. students. For the U.K. students and U.S. students, they clicked the yes button or the forward button, respectively after they read the information statement and agreed to participate in the study. Student consent was followed by a request to complete demographic information and the measures. The author obtained institutional review board approval for the current study and it followed the new European Union Data Protection Regulations.

\section{Results}

Analyses of the data were conducted with SPSS, Version 22 (IBM, 2013) and Mplus 7.11 (L.K. Muthén \& B. O. Muthén, 1998-2013) software. SPSS was used to compute the descriptive statistics, the multivariate analysis of variance (MANOVA) test, and the follow-up analysis of variance (ANOVA) tests, and Mplus was used to conduct the single- and multi-group confirmatory factor analyses (CFAs). DiStefano and Morgan (2014) have advocated for the utilization of the robust weighted least squares means-and-variance adjusted (WLSMV) estimator to analyze categorical data, which were used in the present study. Therefore, the WLSMV parameter estimator was selected and used in conducting the CFAs. Furthermore, latent reliabilities were computed using Raykov's (1997) formula to assess the internal consistency reliability of the TAM-C scale scores.

The six-factor model for the TAM-C was examined separately for eight different groups: U.K. students, U.S. students, females, males, U.K. females, U.K. males, U.S. females, and U.S. males. This process involved conducting single-group CFAs with the data for each of the eight different groups. A parsimony correction index, the root mean square error of approximation, RMSEA, and two incremental indices, the Tucker-Lewis index, TLI, and the comparative fit index, CFI, were selected and used to evaluate the fit of the six-factor model for each of the eight different groups. Good model fit was indicated with the RMSEA value $\leq .06$, the TLI value $\geq .95$, and the CFI value $\geq .95$ (Hu \& Bentler, 1999; Schermelleh-Engel, Moosbrugger, \& Miller, 2003). For an adequate model fit, the following guidelines were used: a RMSEA value $\leq .08$, a TLI value $>.90$, and a CFI value also > .90 (Hu \& Bentler, 1999).

The results of the CFAs indicated a large modification index value between Items 18 and 26, suggesting a correlated error between the two items. These two items were similar in meaning and they were found on the Social Concerns scale. Because these items were similar in meaning and they were on the same scale, a correlated error was added to the model (see Thompson, 2000). After respecification, single-group CFAs were performed again using this model. The modified and unmodified six-factor models for each of the eight different 
groups on the TAM-C are presented in Table 1. The findings indicated that the modified six-factor model for the U.K. students, U.S. students, males, U.K. males, U.K. females, and U.S. males provided an adequate model fit. For females and U.S. females, the modified six-factor model provided a good model fit. Multi-group CFAs followed.

Table 1. Fit Statistics for the Unmodified and Modified Six-Factor Models for Eight Different Groups

\begin{tabular}{llllll}
\hline Group & WLSMV $\chi^{2}$ & df & CFI & TLI & RMSEA [90\% CI] \\
\hline Males & & & & & \\
Six-factor (unmodified) & $3126.14 * * * *$ & 845 & .926 & .921 & $.058[.056, .060]$ \\
Six-factor (modified) & $2971.29 * * * *$ & 844 & .931 & .926 & $.056[.054, .058]$ \\
Females & & & & & \\
$\quad$ Six-factor (unmodified) & $2939.61 * * * *$ & 845 & .949 & .945 & $.051[.049, .053]$ \\
Six-factor (modified) & $2776.69 * * *$ & 844 & .953 & .949 & $.049[.047, .051]$ \\
United Kingdom Males & & & & & \\
$\quad$ Six-factor (unmodified) & $1519.69 * * * *$ & 845 & .932 & .928 & $.055[.050, .059]$ \\
$\quad$ Six-factor (modified) & $1443.30 * * * *$ & 844 & .940 & .936 & $.052[.047, .056]$ \\
United Kingdom Females & & & & & \\
$\quad$ Six-factor (unmodified) & $1486.46 * * * *$ & 845 & .941 & .937 & $.053[.049, .058]$ \\
$\quad$ Six-factor (modified) & $1449.29 * * * *$ & 844 & .945 & .941 & $.052[.047, .056]$ \\
United States Males & & & & & \\
$\quad$ Six-factor (unmodified) & $2192.19 * * * *$ & 845 & .933 & .929 & $.054[.051, .057]$ \\
$\quad$ Six-factor (modified) & $2136.43 * * * *$ & 844 & .936 & .932 & $.053[.050, .056]$ \\
United States Females & & & & & \\
$\quad$ Six-factor (unmodified) & $2215.52 * * * *$ & 845 & .953 & .949 & $.048[.046, .051]$ \\
$\quad$ Six-factor (modified) & $2109.36 * * * *$ & 844 & .956 & .953 & $.046[.044, .049]$ \\
U.K. Students & & & & & \\
$\quad$ Six-factor (unmodified) & $2382.60 * * * *$ & 845 & .929 & .925 & $.059[.056, .061]$ \\
Six-factor (modified) & $2236.44 * * * *$ & 844 & .936 & .932 & $.056[.053, .059]$ \\
U.S. Students & & & & & \\
Six-factor (unmodified) & $3776.25 * * * *$ & 845 & .942 & .938 & $.053[.051, .055]$ \\
Six-factor (modified) & $3584.30 * * * *$ & 844 & .945 & .942 & $.051[.049, .053]$ \\
\hline
\end{tabular}

Note. WLSMV $\chi^{2}=$ robust mean-and-variance adjusted chi square; $\mathrm{df}=$ degrees of freedom; $\mathrm{CFI}=$ comparative fit index; TLI $=$ Tucker-Lewis Index; RMSEA = root mean square error of approximation; $90 \% \mathrm{CI}=90 \%$ confidence interval; $p<.0001$

Multi-group CFAs were performed to determine whether the test anxiety construct, as measured by the TAM-C, is psychometrically equivalent across groups. Psychometric equivalence is needed prior to examining group differences (Putnick \& Bornstein, 2016). This process is known as invariance testing and it involves a series of tests where a more restrictive model is compared to a less restrictive model to determine whether invariance is tenable across groups. As the process continues, the models become more restrictive. The first test conducted is configural invariance where it is determined whether the baseline model has the same form or shape (i.e., the same factor structure) for both groups. Factor coefficients and thresholds are not constrained during this test. In the second test conducted, factor coefficients are constrained to be equal across groups. This test assesses for weak invariance across groups. The final test was strong invariance where the thresholds and factor coefficients are constrained to be equal across groups. Criteria used to determine whether invariance was tenable across groups for each of these three different tests performed were a change in the RMSEA, $\triangle$ RMSEA, $>.015$ and a change in the CFI, $\triangle \mathrm{CFI}$, of $<-.01$ (Chen, 2007). Four different multi-group CFAs were performed to examine country and gender differences on the TAM-C. The four multi-group comparisons included U.K. and U.S. students, males and females, U.K. males and females, and U.S. males and females. The results supported strong invariance across country (United Kingdom and United States) and across gender (males and females; U.K. males and females; and U.S. males and females; see Table 2). 
Table 2. Tests of Measurement Invariance Across Groups

\begin{tabular}{|c|c|c|c|c|c|c|c|c|c|}
\hline Groups & WLSMV $\chi 2$ & $d f$ & $\Delta \mathrm{WLSMV} \chi 2$ & $\Delta d f$ & CFI & TLI & $\Delta \mathrm{CFI}$ & RMSEA [90\% CI] & $\triangle \mathrm{RMSEA}$ \\
\hline \multicolumn{10}{|c|}{ Males and Females } \\
\hline 1. Configural & $5746.264 * * * *$ & 1688 & & & .943 & .939 & & $.052[.051, .054]$ & \\
\hline 2. Weak & $5272.547 * * * *$ & 1725 & $89.511 * *$ & 37 & .950 & .948 & .007 & $.048[.047, .050]$ & .004 \\
\hline 3. Strong & $5705.770 * * * *$ & 1848 & $669.752 * *$ & 123 & .946 & .947 & .004 & $.048[.047, .050]$ & .000 \\
\hline \multicolumn{10}{|c|}{ U.K. Males and Females } \\
\hline 1. Configural & $2892.537 * * * *$ & 1688 & & & .942 & .938 & & $.052[.049, .055]$ & \\
\hline 2. Weak & $2814.984 * * * *$ & 1725 & 52.425 & 37 & .948 & .945 & .006 & $.049[.046, .052]$ & .003 \\
\hline 3. Strong & $3002.901 * * * *$ & 1848 & $288.573^{* * *}$ & 123 & .945 & .946 & .003 & $.049[.045, .052]$ & .000 \\
\hline \multicolumn{10}{|c|}{ U.S. Males and Females } \\
\hline 1. Configural & $4245.883 * * * *$ & 1688 & & & .948 & .944 & & $.049[.047, .051]$ & \\
\hline 2. Weak & $3987.945 * * * *$ & 1725 & $78.630 * *$ & 37 & .954 & .952 & .006 & $.046[.044, .048]$ & .003 \\
\hline 3. Strong & $4287.143 * * * *$ & 1848 & $473.787 * *$ & 123 & .950 & .951 & .004 & $.046[.044, .048]$ & .000 \\
\hline \multicolumn{10}{|c|}{ U.K and U.S. Students } \\
\hline 1. Configural & $5683.048 * * * *$ & 1688 & & & .944 & .940 & & $.052[.050, .053]$ & \\
\hline 2. Weak & $5211.585^{* * * * *}$ & 1725 & $80.314^{* *}$ & 37 & .951 & .949 & .007 & $.048[.046, .049]$ & .004 \\
\hline 3. Strong & $5435.816^{* * * *}$ & 1848 & $331.013 * *$ & 123 & .950 & .951 & .001 & $.047[.045, .048]$ & .001 \\
\hline
\end{tabular}

Note. WLSMV $\chi 2=$ robust mean-and-variance adjusted chi-square; $d f=$ degrees of freedom; $\Delta$ WLSMV $\chi 2=$ change in the robust mean-and-variance adjusted chi-square; $\Delta d f=$ change in degrees of freedom; CFI = comparative fit index; TLI = Tucker-Lewis Index; $\Delta \mathrm{CFI}$ $=$ change in the comparative fit index; RMSEA $=$ root mean square error of approximation; $90 \% \mathrm{CI}=90 \%$ confidence interval; $\Delta \mathrm{RMSEA}=$ change in the root mean square error of approximation; $* p<.05 ; * * p<.01$, **** $p<.0001$

Latent reliabilities were computed for the eight different groups on the six TAM-C scales (see Table 3). Latent reliabilities ranged from .693 to .938 for the U.K. groups (.725 to .934 for U.K. students, .693 to .922 for U.K. males, and .768 to .938 for U.K. females) on the six TAM-C scales. For the U.S. groups, latent reliabilities ranged from .813 to .933 (.813 to .930 for U.S. students, .816 to .921 for U.S. males, and .817 to .933 for U.S. females) on the six TAM-C scales. Furthermore, the range of latent reliabilities on the TAM-C six scales for males and females was .785 to .921 and .802 to .933 , respectively.

Means and standard deviations were computed for U.K. students, U.S. students, males, and females on the TAM-C (see Table 4). A 2x2 MANOVA was then performed with follow-up ANOVAs to examine country and gender differences on the TAM-C. The independent variables were country (United Kingdom, United States) and gender (males, females) and the dependent variables were the six TAM-C scale scores. The results of the MANOVA indicated a country by gender interaction (Wilks' $\Lambda=.99, F(6,1767)=2.47, p<.05, \eta_{p}{ }^{2}=.01$ ), a country difference (Wilks' $\Lambda=.94, F(6,1767)=19.00, p<.001, \eta_{p}{ }^{2}=.06$ ), and a gender difference (Wilks' $\Lambda$ $\left.=.94, F(6,1767)=17.93, p<.001, \eta_{p}{ }^{2}=.06\right)$. Follow-up ANOVAs did not find statistically significant country by gender interactions on the six TAM-C scales. In contrast, statistically significant country differences were found on all of the six TAM-C scales. U.K. students scored higher than U.S. students on the Task Irrelevant Behaviors scale, $F(1,1772)=15.68, p<.001, d=.20$, Physiological Hyperarousal scale, $F(1,1772)=97.90, p$ $<.001, d=.49$, Worry scale, $F(1,1772)=17.71, p<.001, d=.18$, Cognitive Interference scale, $F(1,1772)=12.14$, $p<.01, d=.17$, Social Concerns scale, $F(1,1772)=49.47, p<.001, d=.36$, and Facilitating Anxiety scale, $F(1$, $1772)=15.68, p<.01, d=.16$, with negligible to small effect sizes. In addition, statistically significant gender differences were found on four of the six TAM-C scales. Females scored higher than males on the Physiological Hyperarousal scale, $F(1,1772)=15.68, p<.001, d=.14$, Worry scale, $F(1,1772)=91.68, p<.001, d=.47$, Cognitive Interference scale, $F(1,1772)=6.86, p<.01, d=.13$, and Social Concerns scale, $F(1,1772)=12.19, p$ $<.001, d=.36$, with negligible to small effect sizes. 
Table 3. Latent Reliabilities for Different Groups on the Test Anxiety Measure for College Students (TAM-C)

\begin{tabular}{lllllll}
\hline \multicolumn{7}{c}{ TAM-C } \\
\hline Groups & $\begin{array}{l}\text { Physiological } \\
\text { Hyperarousal }\end{array}$ & Worry & $\begin{array}{l}\text { Cognitive } \\
\text { Interference }\end{array}$ & $\begin{array}{l}\text { Social } \\
\text { Concerns }\end{array}$ & $\begin{array}{c}\text { Task Irrelevant } \\
\text { Behaviors }\end{array}$ & $\begin{array}{l}\text { Facilitating } \\
\text { Anxiety }\end{array}$ \\
\hline U.K. Students & .911 & .934 & .914 & .905 & .725 & .901 \\
U.S. Students & .899 & .930 & .920 & .923 & .813 & .909 \\
Males & .911 & .921 & .911 & .915 & .785 & .893 \\
Females & .908 & .933 & .924 & .929 & .802 & .917 \\
U.K. Males & .914 & .922 & .909 & .905 & .693 & .889 \\
U.K. Females & .909 & .938 & .919 & .927 & .768 & .915 \\
U.S. Males & .903 & .921 & .912 & .919 & .816 & .896 \\
U.S. Females & .899 & .931 & .927 & .928 & .817 & .919 \\
\hline
\end{tabular}

Table 4. Means (M) and Standard Deviations (SD) for Different Groups on the Test Anxiety Measure for College Students (TAM-C)

\begin{tabular}{lllllllll}
\hline \multirow{2}{*}{ Scale } & \multicolumn{2}{l}{ U.K. Students } & \multicolumn{2}{l}{ U.S. Students } & \multicolumn{2}{c}{ Males } & \multicolumn{3}{c}{ Females } \\
\cline { 2 - 9 } & $\mathrm{M}$ & $\mathrm{SD}$ & $\mathrm{M}$ & $\mathrm{SD}$ & $\mathrm{M}$ & $\mathrm{SD}$ & $\mathrm{M}$ & $\mathrm{SD}$ \\
\hline Cognitive Interference & $18.73^{* * *}$ & 5.52 & $17.80^{* *}$ & 5.35 & $17.69^{* *}$ & 5.29 & $18.40^{* *}$ & 5.49 \\
Physiological Hyperarousal & $14.89^{* * *}$ & 5.37 & $12.47^{* * *}$ & 4.51 & $12.82^{* * *}$ & 4.75 & $13.50^{* * *}$ & 5.02 \\
Social Concerns & $15.87^{* * *}$ & 5.50 & $13.94 * * *$ & 5.37 & $14.12^{* * *}$ & 5.26 & $14.85^{* * *}$ & 5.63 \\
Task Irrelevant Behaviors & $13.22^{* * *}$ & 3.59 & $12.49^{* * *}$ & 3.87 & 12.47 & 3.70 & 12.90 & 3.89 \\
Worry & $23.69^{* * *}$ & 5.92 & $22.60^{* * *}$ & 5.95 & $21.43^{* * *}$ & 5.83 & $24.18^{* * *}$ & 5.78 \\
Facilitating Anxiety & $15.19^{* *}$ & 4.20 & $14.50^{* *}$ & 4.30 & 14.84 & 4.24 & 14.60 & 4.32 \\
\hline
\end{tabular}

$* p<.05, * * p<.01, * * * p<.001$

\section{Discussion}

Overall, the findings indicated that the test anxiety construct is psychometrically equivalent across U.K. and U.S. higher education students and males and females on the TAM-C. These findings are similar to the results reported from other cross-national comparisons between U.S. and Australia undergraduate students (Lowe, 2019b) and U.S. and Canadian undergraduate students on the TAM-C (Lowe, 2019a). Moreover, these findings support the use of the TAM-C measure with U.K. students and the same test score interpretation for male and female undergraduate students from the United Kingdom and the United States on the TAM-C. In addition, the majority of the latent reliabilities estimates for the TAM-C scores were adequate, with the exception of the latent reliability found for the U.K. males on the Task Irrelevant Behaviors scale. Based on this lower latent reliability, scores on the Task Irrelevant Behaviors scale should be interpreted with caution for U.K. male students.

Country differences were found on the TAM-C. U.K. students reported statistically significant higher levels of worry, social concerns, cognitive interference, physiological hyperarousal, and task irrelevant behaviors than U.S students. However, only the differences in the worry, physiological hyperarousal, and task irrelevant behaviors between U.K. students and U.S. students were clinically meaningful. It is possible that these clinically meaningful country differences reported in test anxiety in the current study may be related to the examinations U.K. undergraduate students are required to take during their time at U.K. universities. Unlike the exams taken by U.S. undergraduate students, the exams taken by U.K. undergraduate students determine degree classification, such as first class, upper second class, lower second class, etc., when they graduate (Brown, 2011; Mellanby, Zimdars, \& Cortina-Borja, 2013). These exams are reported to be stressful (Chamorrow-Premuzic \& Furnham, 2002) and have significant implications for students' future job prospects (Moneta, Spada, \& Rost, 2007). However, additional research is needed to explore this possibility in more detail. Furthermore, statistically significant country differences were found between U.K. and U.S. undergraduate students on the Facilitating Anxiety factor, with U.K. undergraduate students reporting statistically significant higher levels of facilitating anxiety than U.S. students. However, the difference reported in facilitating anxiety was not clinically meaningful, as the effect size was negligible.

Gender differences were found between male and female students on the TAM-C. Females reported statistically significant higher levels of cognitive interference, physiological hyperarousal, social concerns, and worry than 
males. However, only the difference in worry between males and females was clinically meaningful. von der Embse and colleagues (2018) meta-analysis found positive correlations of .24 to .27 between gender and test anxiety, indicating postsecondary female students reported more test anxiety than postsecondary male students, but these differences were reported based on the total score. Gender differences have been found to be less clear cut at the dimensional level (Lowe, 2018a, b, 2019b; Zeidner \& Nevo, 1992). In contrast, no difference was found in facilitating anxiety between males and females. This finding is in agreement with Lowe's (2018a, 2019b) studies with U.S. and Australian undergraduate students.

U.K. higher education students and females were found to be at a greater risk for test anxiety than U.S. higher education students and males in the present study. The TAM-C developed in the United States and designed specifically for the higher education student population may be an effective instrument in not only identifying test-anxious students in the United States but also in the United Kingdom, so that these students may receive the appropriate interventions needed to reduce their test anxiety. It is imperative that mental health professionals who work with the higher education student population identify test-anxious students early and then develop programs that are effective and readily available for these students to reduce their test anxiety. Ergene (2003) conducted a meta-analysis of different interventions to reduce test anxiety and he found that skill-focused (i.e., test-taking and study skills) approaches in combination with cognitive or behavioral approaches delivered in an individual or group format produced the largest effect sizes in comparison with other treatment approaches. Recently, Reiss and colleagues (2017) conducted a randomized control study with test-anxious university students and found that cognitive behavioral therapy with either relaxation or imagery rescripting and a self-help program delivered in a group format led to significant reductions in students' test anxiety. Studies have shown that there are effective treatment strategies available to reduce university students' test anxiety (Ergene, 2003; Reiss et al, 2017).

The present study has several limitations. There were more females than males who participated in the current study. Therefore, future studies should include a larger percentage of males and replicate the current study and hopefully, yield similar findings. In addition, future studies should examine the TAM-C factor structure in other countries. Along with the examination of the TAM-C factor structure in other countries, cross-national comparisons should be made after measurement invariance has been established in countries of interest. Another limitation associated with the present study was the use of self-report. Future studies should develop other forms of the TAM-C that are completed by informants other than the student, such as instructors, parents, spouses, or close friends to overcome the possibility of self-serving reporting biases. Although additional research is needed, the TAM-C has the potential to assist researchers and mental health professionals in their work with U.K. and U.S. higher education students in the area of test anxiety.

\section{Conclusion}

Research on cross-national comparisons is increasing (Martin, Yu, Papworth, Ginns, \& Collie, 2015), and with an increase, constructs, such as test anxiety, need to be assessed to determine psychometric equivalency prior to examining differences across nations (Putnick \& Bornstein, 2016). In the current study, test anxiety as measured by the TAM-C was found to be psychometrically equivalent across countries and genders, and country and gender differences were noted, with U.K. undergraduate students and females reporting higher levels of test anxiety than U.S. undergraduate students and males. These findings are the first published cross-national comparison to the author's knowledge between U.K. and U.S. higher education students on a new test anxiety measure. Moreover, for researchers and mental health professionals who work with U.K. and U.S. undergraduate students in higher education institutions, these findings have important implications. More specifically, the TAM-C has the potential to assist researchers and mental health professionals in their work with U.K. and U.S. higher education students to study and identify those students who are test anxious, so appropriate interventions can be selected and implemented to reduce their test anxiety.

\section{Acknowledgments}

This work was supported by the University of Kansas under Grants 2338000-906CFI and 2338707-906.

\section{References}

American College Health Association. (2014, Spring). National College Health Assessment II-Reference Group Data Report. American College Health Association. Retrieved from http://www.acha-ncha.org/docs?ACHA-NCHA II_ReferenceGroup_DataReport_Spring.2014

Bodas, J., \& Ollendick, T. H. (2005). Test anxiety: A cross-cultural perspective. Clinical Child and Family Psychology Review, 8, 65-88. https://doi.org/10.1007/s10567-005-2342-x 
Brown, R. (2011). Academic standards: The British experience. Change: The Magazine of Higher Learning, 43, 65-70. https://doi.org/10.1080/00091383.2016.569289

Chamorro-Premuzic, T., \& Furnham, A. (2002). Neuroticism and 'special treatment' in university examinations. Social Behavior and Personality, 30, 807-812. https://doi.org/10.2224/sbp.2002.30.8.807

Chapell, M. S., Blanding, Z. B., Silverstein, M. E., Takahashi, M. N. B., Newman, B., Gubi, A., \& McCain, N. (2005). Test anxiety and academic performance in undergraduate and graduate students. Journal of Educational Psychology, 97, 268-274. https://doi.org/10.1037/0022-0663.97.2.268

Chen, F. F. (2007). Sensitivity of goodness of fit indexes to lack of measurement invariance. Structural Equation Modeling, 14, 464-504. https://doi.org/10.1080/10705510701301834

Distefano, C., \& Morgan, G. B. (2014). A comparison of diagonal weighted least squares robust estimation techniques for ordinal data. Structural Equation Modeling: A Multidisciplinary Journal, 21, 425-438. https://doi.org/10.1080/10705511.2014.915373

Ergene, T. (2003). Effective interventions on test anxiety reduction: A meta-analysis. School Psychology International, 24, 313-328. https://doi.org/10.1177/01430343030243004

Furr, S. R., Westefield, J. S., McConnell, G. N., \& Jenkins, M. J. (2001). Suicide and depression among college students: A decade later. Professional Psychology: Research and Practice, 32, 97-100. https://doi.org/10.1037/0735-7028.32.1.97

Gerwing, T. G., Rash, J. A., Gerwing, A. M. A., Bramble, B., \& Landine, J. (2015). Perceptions and incidence of test anxiety. The Canadian Journal for Scholarship of Teaching and Learning, 6(3), Article 3. https://doi.org/10.5206/cjsotl-rcacea.2015.3.3

Hembree, R. (1988). Correlates, causes, effects, and treatment of test anxiety. Review of Educational Research, 58, 47-77. https://doi.org/10.3102/00346543058001047

Hojat, M., Glaser, K., Xu, G., Veloski, J., \& Christian, E.B. (1999). Gender comparisons of medical students' psychosocial profiles. Medical Education, 33, 342349. https://doi.org/10.1046/ j.1365-2923.1999.00331.x

Hu, L., \& Bentler, P. M. (1999). Cutoff criteria for fit indexes in covariance structure analysis: Conventional criteria versus new alternatives. Structural Equation Modeling, 6, 1-55. https://doi.org/10.1080/10705519909540118

IBM. (2013). IBM SPSS Statistics, Version 22. Chicago: IBM. Institute of Education Sciences. (2016). Comparative indicators of education in the United States and other G-20 countries: 2015. Washington, DC: Institute of Education Sciences: National Center for Education Statistics.

Lewinsohn, P. M., Gotlib, I. H., Lewinsohn, M., Seeley, J. R., \& Allen, N. B. (1998). Gender differences in anxiety disorders and anxiety symptoms in adolescents. Journal of Abnormal Psychology, 107, 109-117. https://doi.org/10.1037/0021-843X.107.1.109

Lowe, P. A. (2018a). An investigation into the psychometric properties of the Test Anxiety Measure for College Students. Journal of Psychoeducational Assessment, 36, 322-336. https://doi.org/10.1177/0734282916678536

Lowe, P. A. (2018b). The Test Anxiety Measure for College Students: Examination of the psychometric properties using an online survey in a Canadian sample. Canadian Journal of School Psychology, 33, 279-296. https://doi.org/10.1177/0829573517725178

Lowe, P. A. (2019a). Exploring cross-cultural and gender differences in test anxiety among U.S. and Canadian college students. Journal of Psychoeducational Assessment, 37, 112-118. https://doi.org/10.1177/0734282017724904

Lowe, P. A. (2019b). Examination of the Test Anxiety Measure for College Students in samples of Australian and U.S. college students. Unpublished manuscript.

Lowe, P. A., Grumbein, M. J., \& Raad, J. M. (2011). Examination of the psychometric properties of the Test Anxiety Scale for Elementary Students (TAS-E) scores. Journal of Psychoeducational Assessment, 29, 503-514. https://doi.org/10.1177/0734282910395894

Lowe, P. A., Lee, S. W., Witteborg, K. M., Pritchard, K. W., Luhr, M. E., Cullinan, C. M., ... Janik, M. (2008). The Test Anxiety Inventory for Children and Adolescents (TAICA): Examination of the psychometric properties of a new multidimensional measure of test anxiety among elementary and secondary school 
students. Journal of Psychoeducational Assessment, 26, 215-230. https://doi.org/10.1177/0734282907303760

Luthra, R. R., \& Flashman, J. (2017). Who benefits most from a university degree?: A cross-national comparison of selection and wage returns in the U.S., U.K., and Germany. Research in Higher Education, 58, 843-878. https://doi.org/10.1007/s11162-017-9451-5

Martin, A. J., Yu, K., Papworth, B., Ginns, P., \& Collie, R. J. (2015). Motivation and engagement in the United States, Canada, United Kingdom, Australia, and China: Testing a multidimensional framework. Journal of Psychoeducational Assessment, 33, 103-114. https://doi.org/10.1177/0734282914546287

Mellanby, J., Zimdarss, A., \& Cortina-Borja, M. (2013). Sex differences in degree performance at the University of Oxford. Learning and Individual Differences, 26, 103-111. https://doi.org/10.1016/j.lindif.2013.04.010

Moneta, G. B., Spada, M. M., \& Rost, F. M. (2007). Approaches to studying when preparing for final exams as a function of coping strategies. Personality and Individual Differences, 43, 191-202. https://doi.org/10.1016/j.paid.2006.12.002

Muthén, L. K., \& Muthén, B. O. (1998-2013). Mplus Version 7.11. Los Angeles, CA: Muthén \& Muthén.

Putnick, D. L., \& Bornstein, M. H. (2016). Measurement invariance conventions and reporting: The state of the art and future directions for psychological research. Developmental Review, 41, 71-90. https://doi.org/10.1016/j.dr.2016.06.004.

Raykov, T. (1997). Estimation of composite reliability for congeneric measures. Applied Psychological Measurement, 21, 173-184. https://doi.org/10.1177/01466216970212006

Reiss, N., Warnecke, I., Tolgou, T., Krampen, D., Luka-Krausgrill, U., \& Rohrmann, S. (2017). Effects of cognitive behavioral therapy with relaxation vs. imagery rescripting on test anxiety: A randomized controlled trial. Journal of Affective Disorders, 208, 483-489. https://doi.org/10.1016/j.jad.2016.10.039

Royal College of Psychiatrists. (2003). The mental health of students in higher education. Council report CR112. London: Royal College of Psychiatrists. Retrieved from https://www.rcpsych.ac.uk/publications/collegereports/cr/cr112.aspx

Sarnoff, I., Lighthall, F. F., Waite, K. S., Davidson, K. S., \& Sarason, S. B. (1958). A cross-cultural study of anxiety amongst American and English school children. Journal of Educational Psychology, 49, 129-136. https://doi.org/10.1037/h0043962

Scanlon, L., Rowling, L., \& Weber, Z. (2007). 'You don't have an identity...you are just lost in a crowd': Forming a student identity in the first-year transition to university. Journal of Youth Studies, 10, 223-241. https://doi.org/10.1080/13676260600983684

Schaefer, B. A., Watkins, M. W., \& Burnham, J. J. (2003). Empirical fear profiles among American youth. Behaviour Research and Therapy, 41, 1093-1103. https://doi.org/10.1016/S0005-7967(02)00258-9

Schermelleh-Engel K., Moosbrugger H., \& Müller H. (2003). Evaluating the fit of structural equation models: Tests of significance and descriptive goodness-of-fit measures. Methods of Psychological Research Online, 8(2), 23-74. http://www.mpr-online.de

Sharp, J., \& Theiler, S. (2018). A review of psychological distress among university students: Pervasiveness, implications and potential points of intervention. International Journal of Advanced Counselling, 40, 192-212. https://doi.org/10.1007/s10447-018-9321-7

Singleton, N., Bumpstead, R., O-Brien, M., Lee, A., \& Meltzer, H. (2001). Psychiatric morbidity among adults living in private household, 2000. London: The Stationary Office.

Sutton, R. M., \& Farrall, S. (2005). Gender, socially desirable responding and the fear of crime: Are women really more anxious about crime?. British Journal of Criminology, 45, 212-224. https://doi.org//10.1093/bjc/azh084

Szafranski, D. D., Barrera, T. L., \& Norton, P. J. (2012). Test Anxiety Inventory: 30 years later. Anxiety, Stress, \& Coping, 25, 667-677. https://doi.org/10.1080/10615806.2012.663490

Thomas, C. L., Cassady, J. C., \& Finch, W. H. (2018). Identifying severity standards on the Cognitive Test Anxiety Scale: Cut score determination using latent class and cluster analysis. Journal of Psychoeducational Assessment, 36, 492-508. https://doi.org/10.1177/0734282916686004

Thompson, B. (2004). Exploratory and confirmatory factor analysis: Understanding concepts and applications. 
Washington, DC: American Psychological Association. https://doi.org/10.1037/10694-000

Triventi, M. (2014). Higher education regimes: An empirical classification of higher education systems and its relationship with student accessibility. Quality and Quantity, 48, 1685-1703. https://doi.org/10.1007/s11135-013-9868-7

University of Leicester. (2002). Student psychological health project. Leicester: University of Leicester. Retrieved from http://www2.le.ac.uk/offices/ssds

von der Embse, N., Jester, D., Roy, D., \& Post, J. (2018). Test anxiety effects, predictors, and correlates: A 30-year meta-analytic review. Journal of Affective Disorders, 227, 483-493. https://doi.org/10.1016/j.jad.2017.11.048

Yusufov, M., Nicoloro-SantaBarbara, J., Grey, N. E., Moyer, A., \& Lobel, M. (2019). Meta-analytic evaluation of stress reduction interventions for undergraduate and graduate students. International Journal of Stress Management, 26, 132- 145. https://doi.org/10.1037/str0000099

Zeidner, M. (1998). Test anxiety: The state of the art. New York: Plenum Press.

Zeidner, M., \& Matthews, G. (2005). Evaluation of anxiety: Current theory and research. In A. J. Elliot, \& C. S. Dweck (Eds.), Handbook of competence and motivation (pp. 141-163). New York: Guilford.

Zeidner, M., \& Nevo, B. (1992). Test anxiety in examinees in a college admission testing situation: Incidence, dimensionality, and cognitive correlates. In K. A. Hagtvet \& B. T. Johnsen (Eds.), Advances in test anxiety research (Vol. 7, pp. 288-303). Lisse, The Netherlands: Swets \& Zeitlinger.

\section{Copyrights}

Copyright for this article is retained by the author(s), with first publication rights granted to the journal.

This is an open-access article distributed under the terms and conditions of the Creative Commons Attribution license (http://creativecommons.org/licenses/by/4.0/). 